\title{
Sobre o papel temático da preposição "com"
}

On preposition "com" ('with') and its thematic roles

Doutor em Letras pela Universidade de São Paulo, Federal da Bahia, afiliado aos grupos de pesquisa Interfaces Linguísticas e Atlas Linguístico do Brasil, onde trabalha com sintaxe e interface sintaxesemântica. (10. http://orcid.org/0000-0002-7255-5422 E-mail: rerissonaraujo@yahoo.com.br Doutora em Língua e Cultura pela Universidade Projeto Vertentes do Português Popular do Estado da Bahia sobre a multifuncionalidade do mais no português popular da Bahia. (iD_http://orcid.org/0000-0002-1923-0530 E-mail: deboractrindade@gmail.com Doutora em Letras pela Universidade Federal da Bahia, onde atua como Professora Associada de Linguistica e Pos-doutoranda na Universidade de pesquisa Interfaces Linguisticas, em que trabalh com morfologia e suas interfaces com a sintaxe e a semântica, tema desenvolvido no projeto de pósdoutoramento, e ao Projeto Vertentes do Português Popular do Estado da Bahia, em que trabalha com o contato entre linguas na formação do português brasileiro, tema de

Recebido em: 10/11/2018 Aprovado em: 10/3/2019

\section{Endereço para correspondência} Rerisson Cavalcante

Instituto de Letras
Universidade Federal da Bahia - UFBA Rua Augusto Viana, SIn - Palácio da Reitoria 40110-060, Salvador, BA, Brasil
Rerisson Cavalcante ${ }^{1}$ Débora Trindade Gomes ${ }^{2}$ Cristina Figueiredo ${ }^{3}$

\author{
Universidade Federal da Bahia, Instituto de Letras, Salvador, BA, Brasil
}

\section{RESUMO}

O artigo apresenta uma tentativa de análise unificada para o papel temático ou contribuição semântica fornecida pela preposição "com" em diversos contextos, incluindo os casos de predicados simétricos e não simétricos em que "com" expressa o mesmo papel semântico de um dos argumentos verbais. A hipótese é que a preposição "com" não expressa ou atribui diferentes papéis aos seus complementos, mas realiza sempre a mesma contribuição semântica, que pode ser caracterizada como a atribuição do traço de "participante do evento" (GOMES, 2017). As interpretações diversas que os complementos de "com" atualizam decorrem da interação entre o traço "participante do evento" e os traços semânticos inerentes ao DP complemento e ao predicado eventivo ao qual o PP está conectado, auxiliados por implicaturas conversacionais.

Palavras-chave: Papéis temáticos. Semântica lexical. Interface sintaxe-semântica. Interface semântica-pragmática.

\section{ABSTRACT}

The paper aims to offer a unified analysis for the thematic role or semantic contribution provided by the preposition "com" ('with') in several contexts in Brazilian Portuguese, including instances of symmetric and nonsymmetric predicates where a com-DP expresses the same thematic role of one of the verbal arguments. Our hypothesis is that the preposition "com" does not express or assign different roles to its complements, but always carries the same semantic contribution, which can be characterized as the feature <participant of the event> (see GOMES, 2017). The different interpretations that "com"-complements manifest result from the interaction between (i) this <participant of the event> feature, (ii) the inherent semantic features of DP's complements, (iii) and the features of the predicate event to which the PP is connected, aided by conversational implicatures.

Keywords: Thematic roles. Lexical semantics. Syntax-semantics interface. Semantics-pragmatics interface. 


\section{Introdução}

$\checkmark$ ste artigo pretende fornecer uma análise unificada para os papéis L temáticos ou contribuições semânticas fornecidas pela preposição "com" em diversos contextos em que essa ocorre. A hipótese de trabalho é que, ao contrário do que se assume, a preposição "com" não expressa ou atribui diferentes papéis aos seus complementos, mas realiza sempre a mesma contribuição semântica, que pode ser caracterizada como o traço de "participante do evento". A hipótese é parcialmente inspirada na classificação dos usos de "com" feita por Ilari et al. (2008) e na proposta de graus de simetria feita Gomes (2017), mas adota uma posição diferente para a motivação e implementação desses usos.

Segundo essa hipótese, as interpretações diversas que os complementos de "com" atualizam decorrem da interação entre: (i) o traço "participante do evento" e os traços semânticos inerentes ao DP complemento; (ii) os traços semânticos do predicado eventivo ao qual o PP está conectado; (iii) e da atuação de princípios pragmáticos na forma de implicaturas conversacionais.

Essa pesquisa se insere nos estudos de interface entre a sintaxe, a semântica e a pragmática das línguas naturais, assumindo o arcabouço teórico da semântica lexical (CANÇADO, 2000), da gramática gerativa e da teoria das implicaturas conversacionais (GRICE, 1975).

\section{A preposição "com"}

Em abordagens baseadas em listas de papéis temáticos relevantes para a sintaxe, a preposição "com" (e seus equivalentes em outras línguas) aparece,

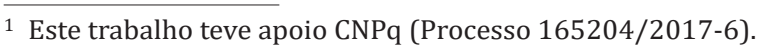

geralmente, associada ao papel temático de instrumento, descrito como o "meio ou entidade pela qual um evento é realizado" ${ }^{2}$. Um levantamento mais detalhado dos contextos em que "com" pode aparecer em português revela, entretanto, um leque muito maior de funções semânticas desempenhadas por essa preposição. Os exemplos abaixo mostram que "com" pode ser associado a cerca de onze papéis temáticos ou funções semânticas diferentes:

I) Agente
(1) a. João viajou com Maria.
b. João assaltou o banco com Pedro.

II) Instrumento
(2) a. João abriu a porta com o pé-de-cabra.
b. João matou Pedro com essa arma.
c. João pagou a conta com o cartão de crédito.

III) Causa/Causador
(3) a. A porta se abriu com o vento.
b. A manteiga derreteu com o calor.
c. João se assustou com a prova/as atitudes de Maria.

IV) Objetivo/Estativo/Objeto de referência
(4) a. João concorda com Pedro.
b. João está com a gente. (= apoia a gente)

V) Tema/Objeto deslocado
(5) a. As mesas foram levadas com as cadeiras para a outra sala.
b. João jogou a carteira fora/no lixo com os documentos. 2 Cf. FILLMORE, 1968, p.46; RADFORD, 1988, p. 372-373; JACKENDOFF, 1990, p. 141; KENEDY, 2013,
p. 162. 
VI) Paciente

(6) a. João casou com Maria. ${ }^{3}$

b. Pedro vai casar a filha (de qualquer jeito) com aquele ricaço.

VII) Beneficiário

(7) a. João dividiu as joias/os presentes (generosamente) com os amigos. ${ }^{4}$

b. 0 jovem repartiu seus bens com os pobres.

VIII) Posse

(8) a. João encontrou Pedro (ontem) com as joias.

b. O bandido foi preso (ontem) com dez passaportes.

IX) Estado mental

(9) a. João deixou Pedro com medo/vergonha.

b. João pagou a conta/contemplou a cena com desgosto.

X) Companhia

(10) a. João está em casa com Maria.

b. João ficou no carro com as crianças.

XI) Tempo

(11) a. João acordou/dormiu com o raiar do dia.

b. Com trinta anos, ele comprou uma casa.

c. A chuva cessou com a chegada da noite. ${ }^{5}$

Algumas observações podem ser feitas sobre os exemplos. Os papéis temáticos apresentados não possuem o mesmo status teórico. Os itens de I a VII (agente, instrumento, causa, objetivo, tema, paciente, beneficiário)

3 Diferentemente de outros autores que consideram os noivos como agentes do evento de casar, consideramos que os argumentos que mudam de estado civil são pacientes, pois passam por mudança de estado. Reservamos o papel de agente para o argumento (se presente) que induz a alteração de estado, que Rervivale o papel de agente para o argumento (se presente) que induz a alteração de estado, que equivale ao celebrante da cerimônia e/ou ao articulador do matrimônio (não da cerimônia 4 em si). Esse ponto, porém, não afeta a argumentação do artigo.

A sentença é ambígua entre uma interpretação agentiva/beneficiária ('João e o amigo dividiram os

5 Note o leitor que os exemplos em (11) têm a interpretação de simultaneidade, não de causalidade. correspondem a papéis mais tradicionais e geralmente mais aceitos na literatura (embora não sem controvérsia), enquanto os itens de VIII a XI (posse, estado mental, companhia e tempo) são muito menos pacíficos. Posse e tempo, em especial, dificilmente seriam considerados papéis temáticos por muitos dos teóricos ${ }^{6}$ ). Mas essa diferença de status não invalida a questão geral, que é a variedade de informações semânticas díspares entre si atribuídas pela preposição a seus complementos, sejam essas compreendidas como papéis temáticos discretos ou não. Ao contrário, esses dados reforçam justamente a pergunta sobre a existência de tais papéis temáticos menos nobres ${ }^{7}$.

Enfim, os dados de (1) a (11) sugerem que o mesmo item lexical é capaz de realizar contribuições ao significado da sentença muito diferentes entre si. São papéis que correspondem a noções muito distintas, como, por exemplo, os de agente e causador, de um lado, e de paciente e tema, de outro.

Esse quadro não é fácil de ser acomodado em uma teoria sobre a atribuição de papel temático. Alguma variabilidade na atribuição de papel temático é perfeitamente aceitável, ligada à própria polissemia no significado dos predicadores. Por exemplo, o verbo "chutar" pode requerer como complemento um DP paciente com o traço [+concreto] ou um tema/objetivo com traço [+abstrato] a depender de ser usado para expressar o evento $<$ ATINGIR ALGO COM O PÉ> (ex.: Pedro chutou a bola/a cadeira/a parede) ou o evento <DAR UM PALPITE SOBRE> (ex.: Pedro chutou todas as respostas na prova). Apesar disso, não pode requerer que o seu complemento seja um agente ou um experienciador. Quanto mais polissêmico é um predicado,

${ }^{6}$ Porém, Perini (2017, p. 258-259), Costa (2009), Silva (2016, p. 102, 142-153) e Diniz (2007, p. 27) consideram a existência desses papéis.

7 Naturalmente, a depender da abordagm, pode-se defender que alguns deles podem ser unificados, como, por exes dén como, por ext a dos papéis temáticos, que diz respeito a són sobre não especificamente à preposição "com". 
mais diferenças de seleção semântica ele poderá ter. Mas essas diferenças parecem ser limitadas, de modo que, por exemplo, um mesmo verbo não atribui aos seus complementos uma variedade tão grande de papéis (nem papéis tão díspares entre si).

É possível que o domínio das preposições lexicais seja inerentemente mais diverso do que o domínio verbal em suas possibilidades de atribuição de papel temático a seus complementos. Mas a questão levantada aqui diz respeito justamente a quais são as propriedades que permitem à preposição "com" essa variabilidade, quais os traços semânticos de "com" que a tornam compatível com esse conjunto específico de relações.

\section{A preposição “com” e o Critério Temático}

Além da diversidade de papéis temáticos, outra questão importante relacionada à preposição "com" diz respeito à hipótese do funcionamento do Critério- $\theta$, segundo o qual cada papel temático deve ser atribuído univocamente a um DP (CHOMSKY, 1981). Em sentenças como (12), o DP introduzido por "com" é associado a papéis distintos dos que recebem os demais argumentos do verbo.

(12) a. [agente João] abriu [paciente a porta] com [instrumento um pé-de-cabra] b. [paciente A porta] abriu com [causador o vento]

Em (13) e (14), por outro lado, "com" parece introduzir o mesmo papel temático que um dos argumentos do verbo.

(13) a. [agente João] tomou café da manhã com [agente a esposa].

b. [agente João] roubou um banco com [agente seus comparsas].

c. João encontrou [tema a filha] ontem com [tema $\mathbf{o}$ namorado]
(14) a. [agente João] transou com [agente a esposa].

b. [agente João] conversou com [agente seus comparsas].

c. [paciente João] casou com [paciente Maria].

Os exemplos em (13) e em (14) diferem em um aspecto. Em (13), os PPs parecem corresponder a adjuntos, não requeridos pelo verbo. Em (14), por outro lado, temos eventos classificados na literatura como recíprocos ou simétricos, em que se requer necessariamente um participante plural. Os PPs introduzem elementos que parecem, em algum nível abstrato, ser coordenados ao argumento do verbo.

Uma possível solução técnica para a questão da equivalência de papéis temáticos e a aparente violação do Critério- $\theta$ seria considerar que os papéis temáticos atribuídos por núcleos lexicais diferentes não são o mesmo papel, apesar de terem o mesmo rótulo. Em outras palavras, é ponto pacífico que, em uma sentença como (15), a existência de dois DPs com o papel temático de agente não é um problema para o Critério Temático, uma vez que tais papéis vêm de predicadores distintos, sendo, então, papéis temáticos distintos.

(15) [agente João] disse que [agente Pedro] consertou o carro.

O mesmo tipo de raciocínio poderia, talvez, ser estendido para os dados em (13). Por essa solução técnica, os papéis temáticos duplicados em (13) estariam de acordo com o Critério Temático, por serem atribuídos por predicadores diferentes: pelo verbo e pela preposição lexical (apesar de ambos fazerem parte do mesmo VP/evento).

Essa solução tem a vantagem de ter uma motivação independente, mas ainda assim depende de como devem ser computados o Critério- $\theta$ e a igualdade/desigualdade de papéis- $\theta$. $O$ cômputo deve ser relativizado (i) a 
cada predicador individual ou (ii) a cada VP/evento/oração? Se o Critério- $\theta$ for computado para cada predicador, os dados (13) não constituem problemas para a Teoria Temática. Se, porém, o Critério- $\theta$ for computado para cada evento/eventualidade, os exemplos de (13) diferem em essência de (15) por expressarem apenas uma eventualidade. (Como veremos adiante, a análise proposta para a semântica de "com" traz uma solução para esses casos de aparente violação do Critério- $\theta$ independentemente da posição que se assume sobre a natureza do seu cômputo).

Ainda que o Critério Temático possa ser computado em função de cada predicador, isso ainda deixa algumas questões em aberto. Primeiro, permanece (de modo ainda mais claro) a questão sobre a diversidade de papéis semânticos expressos pela preposição "com", que é o ponto principal deste trabalho.

Segundo, a solução não se estende necessariamente para os verbos recíprocos, como os de (14), pois o DP introduzido por "com" pode ser considerado um argumento (e não um adjunto) requerido pelo verbo, que exige participantes plurais; e a própria preposição pode ser considerada apenas funcional, e não lexical (uma posição que não estamos assumindo) ${ }^{8}$. Nesse caso, permaneceria a questão sobre como um mesmo papel temático pode ser atribuído a dois DPs distintos, em posições sintáticas diferentes. Voltaremos a esse ponto na próxima seção.

Além disso, há uma questão adicional, que é a variação da atribuição temática com verbos transitivos. A princípio, quando uma sentença tem dois argumentos com os mesmos traços semânticos (por exemplo, duas entidades humanas), um terceiro DP com o mesmo tipo de traço e introduzido por "com" deveria ser associável a qualquer um dos argumentos.

8 Como se verá em 5, a nossa proposta assume que "com" é sempre uma preposição lexical.
Em (16a), por exemplo, o DP “a amante" pode ser interpretado como um tipo de coagente (junto com "João"), como vemos em (16b) ou com um copaciente (junto com "o vizinho"), conforme (16c).

(16) a. [agente João] matou [paciente o vizinho] ontem com [agente/paciente a amante]. b. [agente João e a amante] mataram o [paciente vizinho]. ${ }^{9}$

c. [agente João] matou [paciente $\mathrm{o}$ vizinho e a amante]

Uma sondagem preliminar ${ }^{10}$, entretanto, indicou que a leitura preferencial de (16) é a agentiva. Para alguns falantes, essa é a única leitura disponível. Para outros, ambas as leituras estão disponíveis, mas a agentiva é a mais saliente.

A situação é diferente com (17a), em que a leitura preferencial parece ser a de que o DP "o vizinho" compartilha necessariamente o mesmo papel temático do complemento, como em (17b), e não do sujeito, como em (17c) ${ }^{11}$. A interpretação de que "o vizinho" teria a mesma função semântica que o sujeito, parece ser praticamente bloqueada com esse tipo de predicado. Porém, a troca do verbo por "procurar" inverteria a interpretação do comDP, que passaria ser considerado um coagente.

(17) a. [agente? João] encontrou [paciente a filha] ontem com [paciente o vizinho].

b. = João encontrou [paciente a filha e o vizinho (juntos)]

c. $\neq$ [agente? João e o vizinho (juntos) encontraram a filha (de João)

9 O leitor também deve perceber a ambiguidade adicional ligada à interpretação de "a amante" ser amante de João ou ser amante do vizinho. Nos nossos próprios julgamentos, essa ambiguidade existe em (16a), em quaisquer das duas leituras (agentiva ou não agentiva do terceiro DP); também existe em (16c), que só tem a leitura não agentiva de "a amante”; mas não existe em (16b), que possui leitura apenas agentiva.

${ }^{10}$ Aplicamos testes de aceitabilidade a falantes nativos de português brasileiro, do dialeto baiano (capital e interior), gaúcho e de Brasília. Os informantes tinham que explicitar a interpretação que davam ao tipo de interior), gaúcho e de Brasília. Os informantes tinham que explicitar a interpretação que davam ao tipo de participação no evento do referente expresso pelo DP preposicionado. Os resultados exigem confirmaçã̃o adicional pela ampliação da amostra, mas mostram que ao menos esse é o caso para alguns falantes do PB. propriedades agentivas típicas de volição, controle e/ou desencadeador. 
Nos dois casos, o PP introduz um elemento que é adjunto e não argumento do VP. A questão que fica é qual a propriedade da preposição "com" que faz com que ela tenha uma interpretação distinta em função do tipo do evento, ora orientando-se preferencialmente ao sujeito, ora ao complemento?

\section{Verbos recíprocos e o papel temático}

Uma questão importante sobre os verbos recíprocos é se nas formas descontínuas, como em (18), o DP introduzido pela preposição possui realmente o mesmo papel temático que o argumento introduzido diretamente pelo verbo, sendo sinônimo das formas contínuas, como em (19).

(18) a. João transou com Maria.

b. João conversou com seus comparsas.

c. João casou com Maria.

(19) a. João e Maria transaram.

b. João e Pedro conversaram.

c. João e Maria casaram.

Alguns autores defendem que as formas não são totalmente sinônimas ${ }^{12}$, de modo que o DP introduzido pela preposição "com" expressaria um papel temático diferente daquele do argumento principal. Nesse caso, qual seria exatamente esse papel temático?

A análise a ser proposta aqui é, em princípio, neutra quanto à hipótese de os papéis temáticos serem primitivos teóricos ou resultarem da combinação

${ }^{12}$ Cf. DOWTY, 1991; GODOY, 2008, 2009; GONZÁLEZ, 2008; WACHOWICZ; FRUTOS, 2009. de traços mais primitivos ${ }^{13}$, mas discutiremos brevemente esses dois tipos de análise em que o DP argumento verbal e o DP preposicionado podem, em alguns casos, ser não equivalentes.

Dowty (1991) apresenta uma proposta de tratamento dos papéis temáticos dos verbos em termos de protopapéis, definidos por dois conjuntos de acarretamentos lexicais (lexical entailments) ${ }^{14}$. Os papéis temáticos, assim, seriam reduzidos a protoagente e protopaciente. Os acarretamentos associados ao protoagente seriam:

i) Tem envolvimento volicional no evento ou no estado.

ii) Tem senciência ou percepção.

iii) É causa de um evento ou mudança de estado no outro participante.

iv) Tem movimento relativo à posição do outro participante.

v) Tem existência independente do evento nomeado pelo verbo. Os acarretamentos associados ao protopaciente seriam:

i) Sofre mudança de estado.

ii) É tema incremental.

iii) É afetado causalmente por outro participante.

iv) É estacionário em relação ao movimento do outro participante.

v) Não existe independentemente do evento.

Segundo o autor, as propriedades dos dois conjuntos são relativamente independentes, de modo que um mesmo argumento pode, em princípio, ter quaisquer combinações dessas propriedades. Ainda segundo Dowty, quando um verbo possui dois argumentos, à posição de sujeito (ou argumento

${ }^{13}$ Cf. DOWTY, 1991; CANÇADO, 2003, 2005.

${ }^{14}$ Examinando uma versão preliminar desse trabalho, um parecerista anônimo criticou o uso, nesse trecho, do termo acarretamento, por ser um termo técnico com sentido espeć́fico. No entanto o termo corresponde termo acarretamento, por ser um termo técnico com untido especifico. No entanto, o terno corresponde de implicação equivar

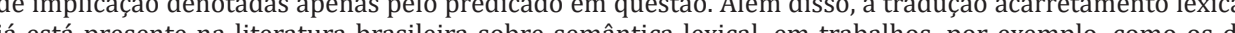
já está presente Cançado (2000) e Godoy (2008). 
externo) estará associado o DP que tiver o maior número de acarretamentos de protoagente; e à posição de complemento (ou argumento interno), estará associado o DP que tiver o maior número de acarretamentos de protopaciente.

Com relação aos verbos recíprocos, Dowty sugere que as formas contínua e descontínua não seriam inteiramente sinônimas ${ }^{15}$. Na forma descontínua, o DP introduzido por "com" diferiria do DP sujeito em pelo menos uma das propriedades listadas acima, de modo a possuir alguns dos acarretamentos associados à noção de protoagente, mas em quantidade menor do que o DP sujeito. Ele exemplifica isso através de dados equivalentes a (20), em que as duas formas são aceitáveis, e a (21), em que a forma contínua é inaceitável, o que sugere que, em (21a), o DP introduzido pela preposição não tem o mesmo status semântico que o DP sujeito.

(20) a. O carro colidiu com o caminhão.

b. O carro e o caminhão colidiram

(21) a. O carro colidiu com o poste.

b. ${ }^{*} 0$ carro e o poste colidiram.

No sistema de Dowty, em que os papéis temáticos não são primitivos teóricos discretos, mas resultados de conjuntos de acarretamentos lexicais, a similaridade parcial entre as funções dos dois DPs das formas descontínuas é compatível com a ideia de que ambos podem possuir propriedades associadas ao modelo de protoagente (ou de protopaciente), mas possuí-las em quantidades distintas. Em (21), nenhum dos dois DPs possui todas as propriedades de protoagente, mas um dos DPs ("o carro") possui, claramente a propriedade "movimento relativo à posição do outro

${ }^{15} \mathrm{O}$ leitor deve ter em mente que nem todos os recíprocos discutidos por Dowty realizam uma preposição do tipo "com"; por exemplo, sentenças como John married Karol. participante", ausente em "o poste". Essa diferença de propriedade seria suficiente para distinguir os dois DPs e associá-los a posições distintas na estrutura sintática.

Godoy (2008), trabalhando dentro do modelo de Cançado (2003; 2005), que trata os papéis temáticos como resultando de quatro propriedades semânticas mais básicas (Desencadeador, Afetado, Estativo e Controle), aponta que a assimetria em (20) e (21) pode ser explicada por uma diferença no traço de Desencadeador e Afetado: o primeiro traço seria compatível com os participantes "o carro" e "o caminhão", mas incompatível com "o poste". Na forma contínua em (20a), ambos os participantes recebem a propriedade Desencadeador. Em (20b) e (21a), apenas "o carro" recebe essa propriedade, enquanto "o caminhão" e "o poste" recebem a propriedade Afetado. Já em (21b), a inaceitabilidade resulta da já citada incompatibilidade entre a propriedade de Desencadeador e o DP "o poste"16.

Godoy (2008) também defende que essa análise baseada em simetria parcial pode ser estendida para outros casos em que também há uma assimetria de movimento entre os dois elementos, como no caso dos complementos de "afastar", em (22), em que a preposição envolvida na alternância é "de" e não "com". Dessa vez, a diferença envolveria as propriedades de Afetado e de Estativo: a primeira é compatível apenas com "a cadeira", o que explica a inaceitabilidade de (22b), em que "a parede" não pode receber a interpretação do tipo de afetação expressa por "afastar". A aceitabilidade de (22a) resulta da interpretação de "a parede" como estativo.

(22) a. Maria afastou a cadeira da parede.

b. *Maria afastou a cadeira e a parede.

${ }^{16}$ Por outro lado, Godoy (2008) aponta que, por exemplo, uma situação em que um poste estivesse rolando ladeira abaixo até se chocar com um carro poderia ser adequadamente descrita por (21b) e a estranheza da sentença se dissiparia, justamente porque agora "o poste" poderia receber a propriedade estranheza da sente 
Godoy (2008, p. 67-68) também aponta que a análise pode ser aplicada aos casos em que há uma assimetria em termos de controle sobre a realização do evento por parte de um dos participantes, como no caso dos argumentos de "concordar" e "conviver", em (23) e (24).

(23) a. Ele concorda com a política de Lula

b. *Ele e a política de Lula concordam.

(24) a. Ela convive bem com a bagunça.

$$
\text { b. *Ela e a bagunça convivem bem. }
$$

A ideia de Dowty (1991) de que a forma descontínua acarreta alguma propriedade a menos do conjunto de acarretamentos de protoagente ou protopaciente consegue descrever adequadamente parte dos dados, mas deixa em aberto algumas questões. A análise dá conta dos casos em que não há alternância entre as duas formas, como em (21), mas deixa em aberto os casos em que há alternância, como em (18), (19) e (20), em que se pode, perfeitamente, associar aos dois DPs o mesmo número de acarretamentos lexicais, isto é, o mesmo número de propriedades de protoagente ou de protopaciente. Não nos parece claro o que a análise de Dowty (1991) deveria prever para esses dados: deveria haver uma distribuição complementar das duas construções (contínua e descontínua) por envolverem necessariamente propriedades diferentes? Ou, se a análise é compatível com pares em que há alternância e em que não há alternância, ou, assumindo que a análise seja compatível com os pares com e sem alternância, o que exatamente permite a alternância mesmo que o conjunto de propriedades é igual nos dois argumentos?

Algo semelhante pode ser dito para a análise de Godoy (2008), baseada em Cançado (2003; 2005), em cujo modelo não há nenhum protopapel, mas existe a seguinte hierarquia temática envolvendo as propriedades de D(esencadeador), A(fetado) e E(stativo), em combinação ou não com $\mathrm{C}($ ontrole):

(25) Hierarquia Temática segundo Cançado (2003; 2005)

$$
\mathrm{D}(\mathrm{C})>\mathrm{D}>\mathrm{A}(\mathrm{C})>\mathrm{A}>\mathrm{E}(\mathrm{C})>\mathrm{E}
$$

Se, porém, as formas descontínuas sempre envolvem uma diferença no conjunto de acarretamentos de protoagente ou protopaciente (ou nas propriedades primitivas propostas por CANÇADO, 2003; 2005), outra pergunta pode ser levantada: Por que a forma descontínua tem esse efeito? A preposição "com" teria o efeito de suprimir ou alterar acarretamentos expressos pelo próprio verbo? Ou a diferença nos acarretamentos é fruto, não da mediação da preposição, mas apenas das propriedades do próprio verbo? No modelo de Dowty, os papéis de protoagente e protopaciente estão relacionados às propriedades do predicado verbal. Se as diferenças de acarretamento entre o argumento principal e o DP introduzido por "com" derivam das propriedades do predicador verbal (e não da preposição), não deveria ser o caso de as sentenças com a forma simples expressarem a mesma ambiguidade, com o DP sujeito (coletivo) podendo ser interpretado em mais de uma forma?

A inexistência da ambiguidade na forma contínua sugere que a diferença de acarretamentos entre as formas contínua e descontínua decorre da contribuição semântica efetuada pela preposição "com". E essa contribuição deve, portanto, ser esclarecida.

Porém, o ponto que nos parece mais importante é que há casos em que as hierarquias sugeridas por Dowty (1991) ou por Cançado (2003; 2005) falham com verbos recíprocos, em que as relações de maior/menor agentividade podem ser expressas de modo inverso, como em (26), em que os DPs preposicionados possuem mais traços de protoagente do que os DPs 
sujeitos, e em que esses, por sua vez, possuem mais traços de protopaciente do que os DPs preposicionados.

(26) Previsões incorretas de inaceitabilidade

a. [paciente Minhas filhas] (fizeram comunhão, crisma e) casaram com [agente o padre Flávio]

b. Noivinhas, [paciente vocês] se casaram com [agente o padre Fernando] com efeito civil?

c. [paciente Eu e meu noivo] vamos casar com [agente um juiz de paz].

As opções que respeitam a hierarquia, com o mesmo tipo de assimetria encontrado em (21) a (24), são claramente bloqueadas nas sentenças em (27), que não podem significar o mesmo que em (26). Tais significados só podem ser expressos com a supressão da preposição "com", como em (27).

(27) Previsões incorretas de aceitabilidade

a. *[agente $O$ padre Flávio] casou com [paciente minhas filhas].

b. * [agente $\mathrm{O}$ padre Fernando] casou com [paciente vocês] com efeito civil?

c. *[agente Um juiz de paz] vai casar com [paciente meu noivo e eu].

Nesse ponto específico, o modelo de Cançado (2003; 2005) parece superior ao de Dowty (1991), pois apresenta uma regra adicional de que todo "argumento que viola a ordem hierárquica aparece na sentença como adjunção, marcado com uma preposição" (CANÇADO, 2005, p. 43). Ainda assim, essa regra, tal como formulada, parece mais uma generalização do que uma explicação. E permanece a questão (fruto da pergunta geral que motiva este artigo): por que o "com" pode introduzir um DP que tem ora um valor mais baixo (em relação aos argumentos do verbo) na hierarquia temática, ora um valor mais alto na mesma hierarquia?
Na próxima seção, apresentamos a proposta de análise para a contribuição semântica da preposição "com". O objetivo é propor uma propriedade que seja ao mesmo tempo específica o suficiente para descrever adequadamente a semântica dessa preposição, mas que permita um grau de vagueza adequado que faça a previsão correta de casos aparentemente problemáticos.

\section{A proposta}

Diante do exposto até aqui, temos os seguintes pontos a serem esclarecidos quanto à contribuição semântica de "com" em diversos contextos, incluindo os casos de alternância e ausência de alternância tanto com verbos recíprocos quanto não recíprocos.

a) A diversidade de papéis temáticos associados ao DP preposicionado.

b) A possibilidade de o DP preposicionado, às vezes, expressar o mesmo papel temático que um dos DPs argumentos do verbo.

c) A possibilidade de, às vezes, o DP preposicionado expressar apenas simetria parcial com as propriedades do argumento verbal.

d) A necessidade de se distinguir (ou não) um status lexical ou funcional nos diferentes usos da preposição "com".

A proposta para dar conta desses e de outros fatos parte da ideia de que "com" não é um item polissêmico, mas indeterminado ou subespecificado. Propomos que a contribuição semântica de "com" nos contextos descritos neste artigo é uniforme e homogênea. A preposição funciona sempre com um núcleo lexical, não funcional, e não atribui papéis temáticos diferentes a seus complementos, mas apenas o traço semântico de "participante do evento". Como será discutido adiante, essa abordagem é baseada em Gomes (2017) e em Ilari et al. (2008). 
Segundo essa análise, as leituras diferentes obtidas pelos complementos de "com" decorrem da interação entre:

i) o traço semântico codificado por "com".

ii) os traços semânticos inerentes do DP introduzido por "com".

iii) os traços do evento expresso pelo predicado.

iv) implicaturas conversacionais.

Essa proposta adota a ideia de que todos os supostos papéis temáticos associados à preposição "com" não são noções primitivas atribuídas por ela a seus complementos, mas decorrem da interação entre esse traço semântico básico <PARTICIPANTE NO EVENTO> com as propriedades semânticas intrínsecas do núcleo do DP complemento e as propriedades semânticas do evento expresso pelo verbo ao qual o PP está concatenado. Isso significa que, nos dados em (1) a (11) a contribuição semântica da preposição é sempre a mesma, marcando a presença ou participação do argumento no evento.

Dessa forma, a interpretação de instrumento, apresentada nos exemplos em (2), repetidos aqui em (28), decorre da propriedade de <PARTICIPAÇão> atribuída pela preposição, conjugada com os traços semânticos [-animado] e [+concreto] presentes nos DPs "pé-de-cabra", "essa arma" e "o cartão de crédito", e com o traço semântico [+dinamicidade] presente nos predicados "abrir", "matar" e "pagar". Isso resulta na inferência de que a participação de uma entidade concreta e sem animacidade em um evento agentivo e dinâmico corresponde a ser utilizada por esse agente dinâmico como meio ou instrumento para a ação.

(28) a. João abriu a porta com o pé-de-cabra.

b. João matou Pedro com essa arma.

c. João pagou a conta com o cartão de crédito.
Já com relação ao que é normalmente considerado como o papel temático de causador, como nos exemplos em (3a-b), repetidos em (29), os DPs introduzidos pela preposição também são [-animados] e [+concretos] ${ }^{17}$ e os eventos são dinâmicos. 0 que faz, então, com que a interpretação dos PPs seja a de causador e não a de instrumento, como nos exemplos anteriores?

(29) a. A porta se abriu com o vento.

b. A manteiga derreteu com o calor.

Isso ocorre, primeiro, porque os DPs "o vento" e "o calor", apesar de [-animados], possuem em si um traço de [+dinamicidade], diferentemente de "o pé-de-cabra", "a arma" e "o cartão de crédito". São nominais eventivos ou quase-eventivos, que podem, portanto, agir como forças desencadeadoras de outros eventos. Além disso, os predicados verbais a que estão ligados através da preposição são dinâmicos, mas ou não possuem traço de agentividade ou não possuem uma expressão explícita dessa propriedade através de um argumento. Os DPs preposicionados, portanto, não podem ser interpretados como agentes dos eventos nem como instrumentos de algum agente.

Raciocínio semelhante explica a interpretação de tema ou paciente nas sentenças em (5), repetidas em (30).

(30) a. As mesas foram levadas com as cadeiras (para a outra sala). b. João jogou a carteira fora/no lixo com os documentos.

Assim como nas demais sentenças, a preposição introduz os DPs como participantes do evento. Em (30a), os traços [-animado], [-dinâmico] e [+concreto] do DP "as cadeiras" o tornam compatível apenas com interpretações que não sejam nem de agente nem de causador; o DP pode

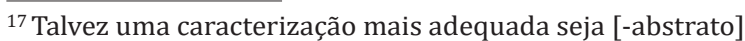


exercer funções como a de elemento afetado pelo evento ou instrumento para a realização do evento. $O$ ponto importante é que essa restrição não é suficiente para determinar que o DP preposicionado seja necessariamente um paciente ou tema. E esta não é uma falha da análise, mas um elemento desejado dela.

A contribuição semântica de "com" permite um grau de vagueza na delimitação da função semântica de seus argumentos que, em alguns casos, é resolvido a partir de inferências (canceláveis, como se verá mais a frente) de natureza pragmática. Assim, a substituição de "as cadeiras" em (30a) por "a corda", por exemplo, permite a interpretação ou como paciente ou como instrumento, apesar de o DP "a corda" ter os mesmos traços [-animado], [-dinâmico] e [+concreto] que o DP "as cadeiras". O que permite essa diferença de interpretação é a entidade "a corda", é em si compatível com a ideia de afetação, mas também com noção de instrumento para a realização de outra ação. Já o DP "as cadeiras" não pode facilmente ser visto como compatível com a noção de um instrumento para um evento de "levar". Além disso, o paralelismo semântico entre "as mesas" e "as cadeiras" (pertencentes ao mesmo campo lexical) ajuda a produzir a inferência de que o papel desempenhado por "as cadeiras" como participante seja paralelo ao de "as mesas".

Outras interpretações apresentadas no início do artigo, como de posse. em (8), companhia em (10) e tempo em (11), também são facilmente explicadas como um simples resultado da informação de que o argumento introduzido por "com" é um elemento copresente no evento descrito, o que resulta em cada uma dessas leituras por inferência a partir das propriedades do próprio DP: um DP humano seria uma companhia, um DP objeto inanimado seria uma possível posse, enquanto um DP eventivo como "raiar do sol", corresponderia a uma simultaneidade de eventos, portanto, marcaria tempo.
Nessa análise, temos uma visão efetivamente composicional da semântica dos PPs introduzidos por "com". Essa preposição não terá diversas opções de s-seleção, cada uma associada a um papel temático distinto, uma análise que é, inclusive, contraintuitiva em relação ao fato de que DPs de naturezas muito diferentes podem ser tomados como seu complemento. As propriedades selecionais de "com" seriam, nessa análise, muito pouco restritivas, permitindo um grande leque de DPs. A função semântica desses DPs introduzidos pela preposição não resulta de um papel temático atribuído por essa, mas da contribuição específica de seus próprios traços semânticos em interação com a noção semântica de <PARTICIPANTE DO EVENTO>, entendida da forma mais neutra possível, como algo que está presente no momento de realização da eventualidade descrita pelo predicado.

Em essência, a proposta é que tal tipo de representação é mais do que suficiente para dar conta da contribuição semântica de um PP introduzido por "com" para o significado da sentença. Em (31), é uma inferência pragmática, baseada na Máxima da Relevância ("por que o falante está me dizendo que 'a esposa' esteve presente no evento de João viajar?"), que faz com que "a esposa", por ser semanticamente um participante de um evento agentivo sem afetação, seja interpretado como necessariamente um tipo de coagente $^{18}$.

(31) João viajou com a esposa.

${ }^{18}$ Em uma semântica de eventos (Cf. PARSONS, 1990), a representação de uma sentença como (i) poderia ter uma representação semelhante a (ii). (Mas esse ponto não é crucial para a proposta do artigo.)

i. João viajou com a esposa.

ii. ヨe (Viajar(e) \& Agente(j, e) \& $\operatorname{Com}($ a esposa, e)

iii. 'Existe um evento e, tal que e é um evento de VIAJAR, e "João" é o agente desse evento e "a esposa" é um participante desse evento.'

E sentenças como (iv) poderiam ter uma representação semelhante a (v).

iv. João vai matar o vizinho (amanhã) com a amante.

iv. João vai matar o vizinho (amanhã) com a amante.

vi. "Existe um evento e, tal que e é um evento de MATAR, e "Ioão" é o agente desse evento, "o vizinho" é o paciente desse evento, e "a amante" é um participante desse evento'. 
Algo semelhante ocorre em dados de verbos transitivos agentivos, como em (32).

(32) João vai matar o vizinho (amanhã) com a amante.

Nesse caso, o fato de que o evento não possui apenas um agente, mas tanto um agente quanto um paciente (ambos humanos), somado ao fato de que o terceiro DP, introduzido por "com" e também [+humano], recebe apenas um traço de participante, permite que este seja, por inferência pragmática, interpretado ou como um coagente ou como um copaciente do evento.

A ideia básica por trás dessa análise da preposição "com" é baseada em Gomes (2017), que, por sua vez, é baseada em Ilari et al. (2008), que propõe que os significados das construções com a preposição "com" se fundam em um esquema cognitivo imagético do tipo espacial, em que o "com" expressa a copresença de um elemento no mesmo espaço físico, como representado na Figura 1 abaixo.

Figura 1 - Esquema imagético da preposição "com"

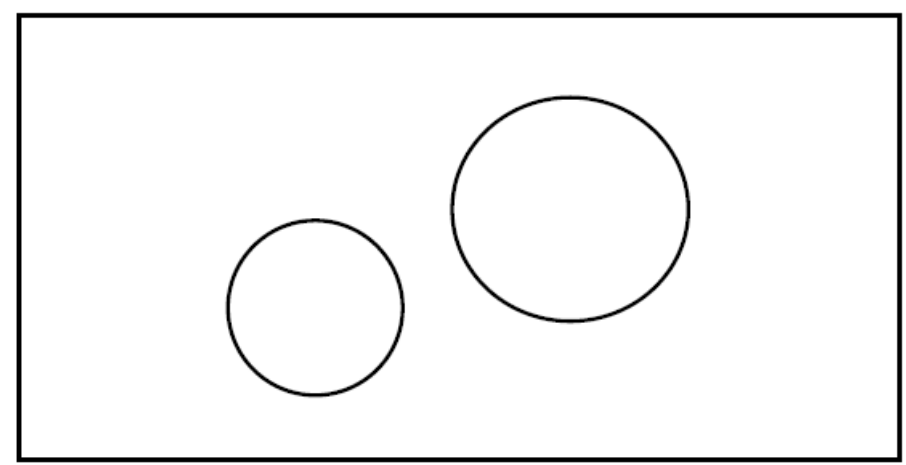

Fonte: Ilari et al. (2008, p. 744).
A abordagem de Ilari et al. (2008) considera as preposições como elementos polissêmicos, cujos distintos significados se baseiam em extensões metafóricas de sentidos espaciais básicos. Ele reconhece dois tipos de significados básicos da preposição "com": os usos comitativos e os de modo. Quanto aos comitativos, considera que o caso prototípico é o comDPs que realizam a mesma ação que o sujeito, mas como um agente paralelo ou secundário, como em (33a). Considera como afastamentos em relação a esse protótipo os casos em que o com-DP expressa apenas a copresença relevante humana (vista como requerida) na ação, com em (33b).

(33) a. O professor não pode sair com o estudante.

b. A linguagem que eu uso com a minha filha é a que eu uso com meus alunos (ILARI et al., 2008, p. 261-262).

Com base nisso, Gomes (2017) (tratando não apenas do uso comitativo de "com", mas também do advérbio "mais") propõe, para os dados de DPs com o valor comitativo, o que considera um continuum de atribuição de papel temático quanto ao "grau de simetria" entre os dois DPs da sentença, como representado na Figura 2. Por esse continuum, um DP comitativo ${ }^{19}$ pode expressar três graus de simetria: (i) uma simetria total, em que o DP preposicionado realiza a mesma ação do DP sujeito; (ii) uma simetria parcial, em que o DP preposicionado atua como um agente secundário ou paralelo; (iii) ou uma assimetria completa, em que o DP preposicionado apenas codifica uma presença (relevante) humana no evento, mas distinta do DP sujeito.

${ }^{19}$ Como apontado, a descrição de Gomes (2017) não é apenas para com-DPs, mas também para mais-DPs, que a conjunção mais desempenha uma função preposicional em que expressa um valor comitativo. 
Figura 2 - Papel semântico do DP comitativo em um esquema continuum

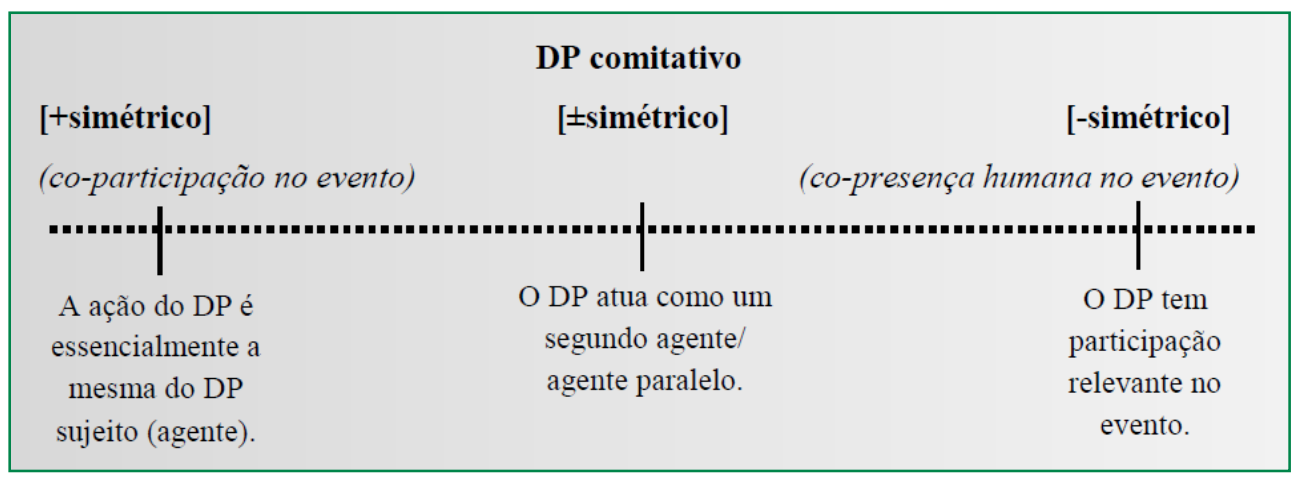

Fonte: Gomes (2017, p. 69).

Ainda segundo Ilari et al. (2008), há um processo de extensão de significado a partir desses usos com DPs humano e animados para produzir os demais usos não animados da preposição "com", expressando noções como as de instrumentos, meios.

A análise apresentada aqui toma como elemento central esse traço ou interpretação de copresença apontados por Ilari et al. (2008) e Gomes (2017), mas difere desses autores em alguns pontos. Primeiramente, apesar de Ilari et al. (2008) considerarem que o esquema imagético básico da preposição "com" seja o de uma copresença espacial, os autores tomam a coagentividade como o caso prototípico e assumem que é a partir desse que há uma perda da prototipicidade (em direção aos casos meramente espaciais), o que nos parece contraditório. Além disso, a proposta deles é baseada em extensões de sentido que criam novos significados que se incorporam nesse item lexical, fazendo com que a preposição "com" seja polissêmica. Na proposta de Gomes (2017), o continuum entre a coparticipação (ativa) e a simples copresença no evento ainda não toma nenhum dos casos como o mais prototípico.
A análise apresentada aqui se baseia nesses dois trabalhos, mas difere deles nos seguintes aspectos: (i) em nossa análise, "com" não é vista como uma preposição polissêmica, mas pouco especificada; (ii) as interpretações distintas não são vistas como resultado de extensões de sentido incorporadas em novos significados da preposição "com"; (iii) em relação a Ilari et al. (2008), a coagentividade não é vista como um caso prototípico a partir do qual as outras interpretações são derivadas; (iv) em relação a Gomes (2017), a coparticipação e a copresença não são vistas como duas possibilidades semânticas alternativas da preposição "com"; (v) ao invés disso, tomamos o caso mais simples e menos especificado, a copresença, não exatamente como o uso prototípico, mas como a única contribuição semântica de "com". As demais interpretações resultam da interação composicional desse traço com os demais traços do DP e do VP mais o auxílio de inferências pragmáticas.

$\mathrm{Na}$ próxima seção, apresentamos algumas evidências de que tal fenômeno envolve em grande parte uma contribuição pragmática, na forma de implicaturas canceláveis, ao invés de uma polissemia semântica.

\section{Evidências em favor da análise}

Como apontado antes, defendemos que "com" não é um item polissêmico, mas que sempre fornece o mesmo tipo de contribuição semântica à sentença (a introdução de um participante adicional cuja atuação não é suficientemente especificada), a partir da qual as interpretações variadas surgem por implicaturas via Máxima da Relevância a partir dos traços semânticos do VP e do DP preposicionado. Evidências em favor dessa análise vêm da cancelabilidade da interpretação dos com-DPs mesmo com verbos simétricos.

Vejamos casos de um com-DP interpretado como copaciente. Em (33), por exemplo, a leitura de copaciente de "João" pode ser cancelada por uma continuação. 
(33) a. [paciente Várias mulheres] (se) casaram com [paciente João].

b. [paciente Várias mulheres] (se) casaram com [agente João]. Ele é um ótimo celebrante.

c. [paciente Maria] (se) casou com [paciente João].

b. [paciente Maria] (se) casou com [agente João]. Ele é um ótimo celebrante.

Algo semelhante ocorre em (34) em que o DP "a mãe", normalmente interpretado como um coagente em relação a "conversar" em (34a), passa a figurar como um participante no sentido mais simples possível: apenas uma copresença no evento, sendo duvidoso que exerça sequer a função de paciente.

(34) a. [agente João] conversa com [agente a mãe] todos os dias.

b. [agente João] conversa com [paciente/estativo a mãe] todos os dias (pois os médicos disseram a ele que pessoas em coma ouvem o que acontece em volta).

Note que a interpretação presente em (34b) não pode ser expressa através de outras configurações, como mostra (35).

(35) a. \#João e a mãe conversam todos os dias (pois os médicos disseram a ele que pessoas em coma ouvem o que acontece em volta).

b. \#A mãe de João conversa com ele todos os dias (pois os médicos disseram a ele que pessoas em coma ouvem o que acontece em volta).

O interessante de casos como em (34), além da cancelabilidade, é o fato de que esta resulta em um com-DP ser interpretado como um mero paciente ou mesmo um objeto estativo, não previsto nem pela grade temática nem pelas propriedades intrínsecas do verbo "conversar". A esse respeito, os dados a seguir são ainda mais reveladores.
Imaginem uma situação em que João entra escondido na casa de Maria, enquanto ela dorme, e mantém relações sexuais com ela, sem que ela acorde. Nesse caso, apenas a sentença (36a) pode ser usada como uma descrição adequada da situação. Há uma clara assimetria entre o DP "João", interpretado como agente, e o DP preposicionado "Maria", que é interpretado mais adequadamente como um paciente. Notem que esses dados já são curiosos, porque o papel de paciente não é tido como algo previsto na grade argumental de um verbo como "transar". A interpretação de paciente é causada pela sequência "enquanto ela dormia", que cancela a interpretação default de coagentividade.

\section{(36) Cenário 1: Estupro.}

a. [agente João] transou com [paciente Maria] (enquanto ela dormia).

b. \#João e Maria transaram (enquanto ela dormia).

c. \#Maria transou com João (enquanto ela dormia).

Imaginemos agora outra situação. João e Maria são casados. Maria é sonâmbula; acorda no meio da noite e faz várias coisas: arruma a casa, anda pela sala, fala com as pessoas e, às vezes, até mantém relações sexuais com seu marido, mas sem acordar. Essa situação pode ser descrita adequadamente por todas as sentenças em (36), repetidas em (37), inclusive por $(37 \mathrm{c})$.

(37) Cenário 2: Sonambulismo

a. [agente João] transou com [agente Maria] (enquanto ela dormia).

b. [agente João e Maria] transaram (enquanto ela dormia).

c. [agente Maria] transou com [agente João] (enquanto ela dormia).

Aparentemente, esses dados seriam apenas uma variação do fato já discutido por Dowty (1991) de assimetria de traços na forma descontínua dos predicados simétricos. Entretanto, dois pontos devem ser observados. 
Primeiro, nos dados em (36), não existe nenhuma incompatibilidade intrínseca entre o DP "Maria" e as propriedades associadas ao protoagente ou a Desencadeador com controle, diferentemente do que ocorre com "o poste” em (21). É a continuação da sentença (além de dados contextuais) que cancela a interpretação que seria default. Se a interpretação é cancelável, é de natureza pragmática, não semântica.

Segundo, nesse cenário em (37), o DP "Maria" tem propriedades agentivas, mas não é nada claro que tenha mais propriedades de protoagente do que "João", que é quem tem efetivamente controle de suas ações e percepção da situação. Ainda assim, o DP "Maria” pode aparecer como sujeito, e o DP "João" pode aparecer preposicionado.

Outra evidência em relação a isso diz respeito a dados em que o com-DP introduz um terceiro participante em um VP transitivo que já conta com dois DPs argumentos com papéis temáticos diferentes, como em (16a), repetido aqui em (38a), com "matar", em que, inicialmente, o com-DP pode ser interpretado como agente ou paciente, mas com uma tendência para que a interpretação agentiva do DP preposicionado seja a mais saliente ou a única disponível (ao menos para alguns falantes). A hipótese de que isso é um processo pragmático e não sintático-semântico pode ser confirmada pelo fato de que essa interpretação agentiva pode ser facilmente cancelada, como em (38b), em que a única interpretação possível para o DP preposicionado é a de paciente.

(38) a. [agente João] matou [paciente $\mathrm{O}$ vizinho] ontem com [agente $\mathbf{a}$ amante]. b. [agente João] matou [paciente $\mathrm{O}$ vizinho] ontem com [paciente $\mathbf{a}$ amante] e enterrou os corpos no quintal.

A possibilidade de cancelamento da interpretação do DP preposicionado sugere que os supostos papéis temáticos atribuídos por "com" não são traços semânticos, mas implicaturas conversacionais no sentido de Grice (1975).

Essa análise também explica o motivo para a diferença de "grau de simetria" ou "grau de agentividade", nas palavras de Godoy (2008), González (2008) e Gomes (2017), que ocorre entre os DPs de construções descontínuas com verbos simétricos. Se o DP introduzido por "com" é marcado apenas como "participante do evento", a natureza da participação estará sujeita a uma inferência a partir das demais propriedades do predicado, mas também de informações contextuais sobre a situação. Nesse processo de inferência, o DP preposicionado pode ser visto como realizando o mesmo tipo de participação que o argumento verbal (agente ou paciente), como em (39), ou contendo uma participação apenas parcialmente semelhante ao argumento verbal, como em (21), repetido com (40).

(39) a. João trabalhou com Maria.

b. João assaltou o banco com Pedro.

(40) a. O carro colidiu com o poste.

b. ${ }^{*} \mathrm{O}$ carro e o poste colidiram.

O ponto importante aqui é que, ao contrário do que sugere Godoy (2008), isso não decorre da incompatibilidade dos participantes com as restrições selecionais do verbo, mas de um mecanismo de compatibilidade por inferência, que pode ser cancelado por informações contextuais, pragmáticas.

\section{Considerações finais}

Apresentamos aqui uma proposta de análise para a contribuição semântica da preposição "com" segundo a qual a diversidade de papéis 
temáticos a ela associada não resulta de uma ampla polissemia e variabilidade desse item, mas, ao contrário, de este sempre exercer a mesma contribuição semântica básica, indicando simplesmente que o seu complemento é um elemento participante ou copresente no evento ou situação.

Por essa análise, as leituras de agente, paciente, instrumento, causador etc., são derivadas por um processo pragmático de inferência, provavelmente via implicaturas conversacionais, que podem ser canceladas em situações específicas cujas restrições precisam ser mais bem examinadas.

A necessidade de postular a ação de implicaturas conversacionais ligadas à preposição "com" é uma necessidade teórica independente, devido a situações em que a alternância de ordem entre DPs conectados (direta ou indiretamente) pela preposição "com" resulta em diferenças de interpretação na relevância dos itens, apesar de não resultar em diferenças de papel temático, como nos casos em (41).

(41) a. Meu pai não come pizza com catchup, ele come catchup com pizza

b. João não trabalha com Maria; Maria (é que) trabalha com João.

c. Não foi Pedro que roubou o banco com João, foi João que roubou o banco com Pedro.

d. Natália não toma café com leite, ela toma leite com café.

Essa diferença de "grau de importância" atribuído ao primeiro elemento (o DP não preposicionado) em relação ao segundo (o preposicionado) não pode ser facilmente captada em termos das propriedades de acarretamento lexical propostas por Dowty (1991), nem dos primitivos semânticos (Desencadeador, Afetado e Estativo, com ou sem Controle) propostos por Cançado (2003; 2005).

A atuação de um mecanismo de implicatura conversacional é capaz de dar conta disso. Essa implicatura seria semelhante àquela associada à conjunção "e" em sentenças como (42), em que a primeira sentença de uma coordenação é interpretada como descrevendo um evento temporalmente anterior ao da segunda sentença, na ausência de qualquer informação adicional. Essa interpretação pode ser facilmente cancelável, como em (43).

(42) a. João chegou e Maria saiu. Implicatura: 'João chegou e, depois, Maria saiu'.

b. Maria saiu e João chegou. Implicatura: 'Maria saiu e, depois, João chegou'.

(43) a. João chegou e Maria saiu (depois de falar com ele).

b. João chegou e Maria saiu. Mas não nessa ordem.

Em princípio, é possível que esse traço semântico de participação ou copresença no evento possa ser traduzido como equivalente ao papel temático Companhia ou Comitativo, mas entendido agora de modo bem mais abrangente do que costumeiramente recebe na literatura linguística sobre papéis temáticos. Ou seja, Companhia não seria um dos papéis atribuídos por "com", mas sim o único papel que essa preposição codifica. Outro caminho para interpretar essa proposta é considerá-la um desenvolvimento da proposta de Dowty (1991) quanto aos protopapéis em direção ao domínio da adjunção ou dos argumentos das preposições (já que sua proposta focava apenas na realização dos dois argumentos verbais): "com" atribuiria um papel de protoparticipante, neutro entre os papéis de protoagente e de protopaciente.

Por fim, fica em aberto, para um futuro trabalho, quais seriam as consequências dessa proposta para as teorias sobre papéis temáticos em geral como primitivos teóricos. 


\section{Referências}

CANCADO, Márcia. O papel do léxico em uma teoria dos papéis temáticos. DELTA, São Paulo, v. 16, n. 2, p. 297-321, 2000. https://doi.org/10.1590/S0102-44502000000200004

CANCADO, Márcia. Hierarquia temática: uma proposta para o PB. Revista Letras, Curitiba, n. 61, p. 17-43, 2003. https://doi.org/10.5380/rel.v61i0.2880

CANÇADO, Márcia. Posições argumentais e propriedades semânticas. DELTA, São Paulo, v. 21, n. 1, p. 23-56, 2005. https://doi.org/10.1590/S0102-44502005000100002

CHOMSKY, Noam Lectures on Government and Binding. Dordrecht: Foris Publications, 1981.

COSTA, Igor de Oliveira. A interface sintaxe-semântica: elementos de valor temporal em posições não-prototípicas. Revista Gatilho, Juiz de Fora, ano V, v. 9, s/p., mar. 2009.

DINIZ, Carolina Ribeiro Diniz. Eu te amo você. O redobro de pronomes clíticos sob uma abordagem minimalista. 2007. 155f. Dissertação (Mestrado) - Universidade Federal de Minas Gerais, Belo Horizonte, 2007.

DOWTY, David. Thematic proto-roles and argument selection. Language, v. 63, n. 3, p. 547-617, 1991. https://doi.org/10.2307/415037

FILLMORE, Charles J. The Case for Case. In: BACH, Emmon; HARMS, Robert Thomas. (ed.). Universals in Linguistic Theory. London: Holt, Rinehart and Winston, 1968. p. 1-88.

GODOY, Luisa. Os verbos recíprocos no PB e a hipótese da determinação semânticolexical sobre a sintaxe. Alfa, São Paulo, v. 53, n. 1, p. 283-299, 2009.

GODOY, Luisa. Os verbos recíprocos no PB: interface sintaxe-semântica lexical. 2008. 86f. Dissertação (Mestrado) - Universidade Federal de Minas Gerais, Belo Horizonte, 2008.

GOMES, Débora Carvalho Trindade. O uso variável do "mais" no português afrobrasileiro: coordenação e subordinação. 2017. 124f. Dissertação (Mestrado) Universidade Federal da Bahia, Salvador, 2017.
GOMES, Débora Carvalho Trindade; FIGUEIREDO, Cristina. O uso do 'mais' no português rural afro-brasileiro. LETRÔNICA, Porto Alegre, v. 6, p. 269-287, 2013.

GONZÁLEZ, Lara Frutos. Os verbos simétricos no PB. 2008. 28f. Trabalho de Conclusão de Curso (Graduação) - Universidade Federal do Paraná, Curitiba, 2008.

GRICE, Paul. Logic and conversation. In: COLE, Peter; MORGAN, Jerry. (ed.). Syntax and Semantics, v. 3: Speech Acts. New York: Academic Press, 1975. p. 41-58.

ILARI, Rodolfo; CASTILHO, Ataliba; ALMEIDA, Maria Lúcia; KLEPPA, Lou-Ann; BASSO, Renato Miguel. A preposição. In: ILARI, Rodolfo. Gramática do português culto falado no Brasil: volume IV - Palavras de classe fechada. Campinas: Editora da Unicamp, 2008 p. 163-310.

JACKENDOFF, Ray. Semantic Structures. Cambridge: MIT Press, 1990.

KENEDY, Eduardo. Curso básico de gramática gerativa. São Paulo: Contexto, 2013.

PERINI, Mário A. Gramática descritiva do português brasileiro. Rio de Janeiro: Vozes, 2017

PARSONS, Terrence. Events in the Semantics of English. Cambridge: MIT Press, 1990.

RADFORD, Andrew. Transformational Grammar: a first course. Cambridge: Cambridge University Press, 1988. https://doi.org/10.1017/CB09780511840425

SILVA, Fellipe Fernandes Cavallero da. Um recorte funcionalista da aspectualidade do Pretérito Perfeito Composto em Português do Brasil e sua relevância para o Português como Segunda Língua para Estrangeiros (PL2E). 2016. 192f. Tese (Doutorado) Pontifícia Universidade Católica do Rio de Janeiro, 2016

WACHOWICZ, Tereza Cristina; FRUTOS, Lara. Uma abordagem semântica dos verbos simétricos do PB. Diacrítica, Braga, v. 24, p. 449-470, 2009. 